\title{
CALCULATION OF GAMMA-RAY ATTENUATION PARAMETERS FOR LOCALLY DEVELOPED ILMENITE-MAGNETITE CONCRETE
}

\author{
MD. HOSSAIN SAHADATH, RIPAN BISWAS, MD. FAZLUL HUQ* AND \\ ABDUS SATTAR MOLLAH ${ }^{1}$ \\ Department of Nuclear Engineering, University of Dhaka, Dhaka-1000, Bangladesh
}

\begin{abstract}
The mass attenuation coefficients $(\mu / \rho)$ of locally developed ilmenite-magnetite (I-M) concrete over a wide range of photon energy were calculated analytically using Matlab and compared with the values obtained from widely used XCom computer program. A good agreement between the calculated and XCom generated value was found. The linear attenuation coefficients and relaxation lengths were calculated for the same energy range. The transmission curves were drawn for some common gamma-ray energies and half value layer and tenth value layer were calculated. The results of this study will provide some useful information about the shielding material data base for practical shielding calculation. The results will also illustrate the effectiveness of I-M concrete so far as its shielding properties are concerned.
\end{abstract}

Key words: Gamma ray, Mass attenuation coefficient, Linear attenuation coefficient, Half value layer, Tenth value layer, Relaxation length

\section{INTRODUCTION}

Because of the wide application of nuclear science and technology in various fields as nuclear power plant, nuclear research reactor, medical centers, industries, laboratories and research facilities, both the radiation workers and the member of the general public are exposed to ionizing radiation intentionally and unintentionally. Therefore, adequate and effective shielding is a prerequisite for the installation of such nuclear facilities to keep the radiation exposure below the dose limits recommended by the International Commission on Radiological Protection (ICRP). Most of these shields are made from different types of concretes, such as ordinary concretes, heavy concretes (e.g., barite, serpentine, steel magnetite, ilmenite, magnetite) etc. depending on the energy, type of radiation, availability of the shielding material, taking into account of the state of technology, the economics of reducing exposures relative to the benefits to be achieved and other relevant socioeconomic factors. The heavy concretes proved themselves as best

\footnotetext{
*Corresponding author: <fazlul.huq@du.ac.bd>.

${ }^{1}$ Department of Nuclear Science and Engineering, Military Institute of Science and Technology, Dhaka, Bangladesh.
} 
suitable materials for the attenuation of gamma radiation. Several investigators have worked on the shielding properties of concretes and building materials such as Sharifi et al. (2013), El-Khayatt et al. (2013), Yilmaz et al. (2011), El-Khayatt (2010), Akkurt et al. (2010), Akkurt et al. (2012), Akkurt et al. (2013), Akkurt et al. (2006), Oto et al. (2013), Stankovic et al. (2010).

The ilmenite-magnetite concrete I-M concrete is also a heavy concrete developed locally with sand stone chips, and cements in $100: 100: 36$ ratio by volume, respectively. It has been used as the biological shield of the 3MW (Thermal) TRIGA Mark II Research Reactor at the Atomic Energy Research Establishment (AERE) in Bangladesh. The gradation and composition of its aggregates are shown in Table 1 and the elemental composition is shown in Table 2. Some shielding parameters of this material have been investigated using a ${ }^{252} \mathrm{Cf}$ spontaneous fission source and reactor neutron beam by Ahmed et al. (1992), Bhuiyan et al. (1991), Ahmed et al. (1999) and Mollah et al. (1992). These studies were restricted to the neutron attenuation. There are almost no reports on the study of mass attenuation coefficients, linear attenuation coefficient, relaxation length and HVL, TVL for different gamma photon energies. This encouraged the present authors to carry out this work. The objective of this study is to generate a data base for these attenuation parameters of locally developed I-M concrete which will facilitate the shielding design problems.

\section{THEORETICAL BACKGROUND}

If a material of thickness $x$ is placed in the path of a beam of gamma radiations, the intensity of the beam will be attenuated according to the Beer-Lambert's law,

$$
\frac{I}{I_{0}}=e^{-\mu x}
$$

where, $\mathrm{I}_{0}$ and $\mathrm{I}$ are the unattenuated and attenuated photon intensities, respectively and $\mu$ $\left(\mathrm{cm}^{-1}\right)$ is the linear attenuation coefficient of the material.

A coefficient that characterizes a given material more accurately is the densityindependent mass attenuation coefficient $\mu / \rho\left(\mathrm{cm}^{2} / \mathrm{g}\right)$. The mass attenuation coefficient for a mixture is given by,

$$
\frac{\mu u}{\rho}=\sum_{i} w_{i}\left(\frac{\mu}{\rho}\right) i
$$

where, $\rho$ is the physical density of the sample, and $w_{i}$ and $\left(\frac{\mu}{\rho}\right) i$ are the weight fraction and mass attenuation coefficient, respectively of the ith element of the mixture. 
The linear attenuation coefficient of a mixture is given by,

$$
\mu=\sum_{i} \rho_{i}\left(\frac{\mu}{\rho}\right) i
$$

where, $\rho_{i}$ is the partial densityof $\mathrm{i}^{\text {th }}$ constituent element. It is given by the product of the weight fraction of $i^{\text {th }}$ constituent $w_{i}$ and the density of the sample $\rho$ as the follows,

$$
\rho_{i}=w_{i} \rho
$$

The half value layer (HVL) is defined as the thickness of a shield or an absorber that reduces the radiation level by a factor of 2 that is to half the initial level. Mathematically,

$$
\mathrm{HVL}=\frac{0.693}{\mu}
$$

A shield that will attenuate a radiation beam to $10 \%$ of its radiation level is called a tenth value layer (TVL) and is given by,

$$
\mathrm{TVL}=\frac{2.30}{\mu}
$$

The relaxation length of the photon is given by,

$$
\lambda=\frac{1}{\mu}
$$

\section{MATERIALS AND METHODS}

Different computer codes are used worldwide to simulate the transport of photons through three dimensional materials which include MCNP-4C (Sharifi et al. 2013), FOTELP-2K6 (Stankovic et al. 2010) etc. The mass attenuation coefficients were calculated analytically using in-house developed Matlab program. For the validation, the results were compared with the results obtained from widely used XCom computer program. This program is based on mixture rule to calculate the partial and total mass attenuation coefficients for all elements, compounds and mixtures at standard as well as selected energies. The mass attenuation coefficients for the elements at different energies were taken from Hubbel et al. (1994). For comparison, the attenuation parameters for other types of concretes were also calculated by using in-house developed Matlab and XCom programs. The composition of barite, serpentine and ordinary concrete-1 were taken from Sharifi et al. (2013) and ordinary concrete-2 from Cember and Johnson (2009). 
Table 1. I-M concrete aggregates.

\begin{tabular}{ll} 
Coarse aggregate [stone chip gradation (vol. \%)] \\
$3.81 \mathrm{~cm}$ down - 20 black (crusher) \\
$2.54 \mathrm{~cm}$ down - 30 black (crusher) \\
$1.91 \mathrm{~cm}$ down - 35 black (crusher) \\
$1.27 \mathrm{~cm}$ down - 15 black (crusher) \\
\hline Fine aggregate composition (vol. \%) \\
\hline Ordinary sand & 20 \\
Ilmenite & 40 \\
Magnetite & 40 \\
Mix ratio (cement : sand : stone : chips) & $36: 100: 100$ \\
Net water/cement ration & 0.5 \\
Slump (cm) & 1.27 \\
\hline
\end{tabular}

Table 2 Elemental composition of I-M concrete.

\begin{tabular}{ccccc}
\hline Element & $\begin{array}{c}\text { Atomic } \\
\text { number }\end{array}$ & $\begin{array}{c}\text { Elemental density } \\
\left(\mathrm{g} / \mathrm{cm}^{3}\right)\end{array}$ & $\begin{array}{c}\text { Weight } \\
\text { fraction }\end{array}$ & $\begin{array}{c}\text { Total ensity } \\
\left(\mathrm{g} / \mathrm{cm}^{3}\right)\end{array}$ \\
\hline $\mathrm{H}$ & 1 & 0.0157 & 0.00564780 & \\
$\mathrm{O}$ & 8 & 1.0523 & 0.37852518 & \\
$\mathrm{C}$ & 6 & 0.0022 & 0.00079137 & \\
$\mathrm{Mg}$ & 12 & 0.1014 & 0.03647482 & \\
$\mathrm{Al}$ & 13 & 0.0497 & 0.01787770 & \\
$\mathrm{Si}$ & 14 & 0.1349 & 0.04852518 & \\
$\mathrm{P}$ & 15 & 0.0002 & 0.00007194 & 2.78 \\
$\mathrm{~S}$ & 16 & 0.0016 & 0.00057554 & \\
$\mathrm{Ca}$ & 20 & 0.2469 & 0.08881295 & \\
$\mathrm{Ti}$ & 22 & 0.3563 & 0.12816547 & \\
$\mathrm{~V}$ & 23 & 0.0021 & 0.00075540 & \\
$\mathrm{Cr}$ & 24 & 0.001 & 0.00035971 & \\
$\mathrm{Mn}$ & 25 & 0.0084 & 0.00302158 & \\
$\mathrm{Fe}$ & 26 & 0.7863 & 0.28284173 & \\
$\mathrm{Ni}$ & 28 & 0.0012 & 0.00043165 & \\
\hline
\end{tabular}

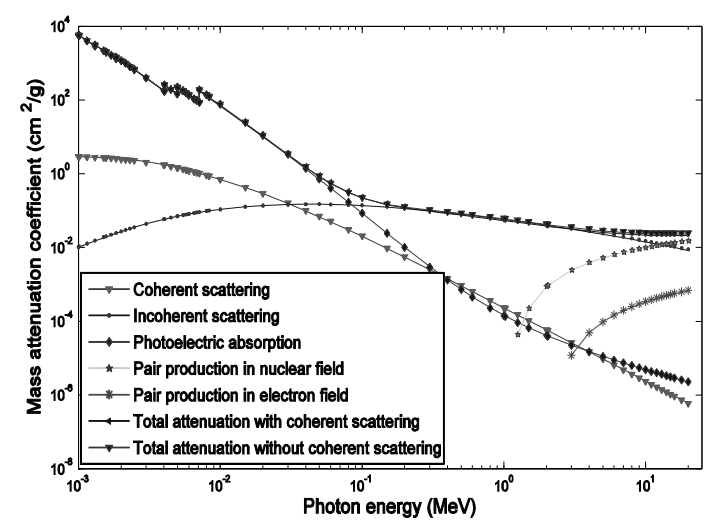

Fig. 1. Variation of mass attenuation coefficients of I-M concrete with photon energy in different interactions. 


\section{RESULTS AND DISCUSSIONS}

The mass attenuation coefficients of I-M concrete at different photon energies are shown and are compared with other concretes of different densities and compositions in Figs 1 - 3. Three interaction processes are contributed to the attenuation of photon over the whole energy range. These are the photoelectric absorption which is dominant in the low energy range of about 10 to $100 \mathrm{keV}$, Compton scattering which is an incoherent scattering of photon and is dominant in the intermediate energy region of 0.1 to $10 \mathrm{MeV}$ and finally the pair production which is dominant in the high energy region of greater than $10 \mathrm{MeV}$. These energy ranges differ slightly from material to material. In the energy range where photoelectric absorption is dominant, mass attenuation coefficient decreases sharply with photon energy. This is because cross section for this reaction varies approximately as $Z^{4} / \mathrm{E}^{3}$. The photoelectric absorption falls smoothly with increasing photon energy but rises again as the energy reaches the photoelectric edge $E_{k}$ or $E_{l}$, i.e. the binding energy of $\mathrm{K}$ or $\mathrm{L}$ shell electrons. The mass attenuation coefficients of I-M concrete are found higher than the ordinary concretes and serpentine. It is due to the very strong dependence of photoelectric absorption on the atomic number and the higher effective atomic number of I-M concrete. Barite which has the highest effective atomic number among these concretes has the highest value of $(\mu / \rho)$. In the intermediate energy region, $(\mu / \rho)$ decreases slowly with increasing energy and nearly same for all concretes. This is because of the dominance of the compton scattering which is independent of the atomic number of the element and depends only on the electron density per unit mass.

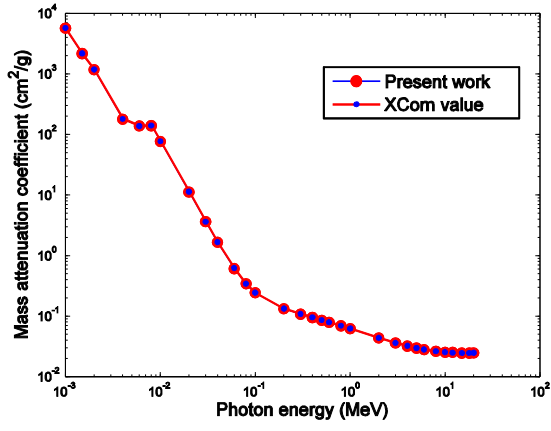

Fig. 2. Variation of total mass attenuation coefficients of I-M concrete with photon energy.

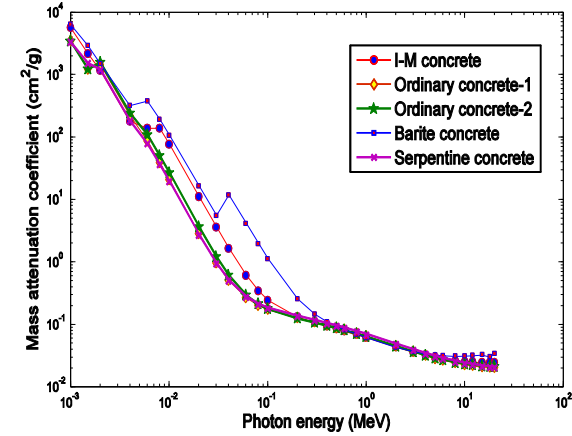

Fig. 3. Variation of total mass attenuation coefficients of different concretes with photon energy.

Linear attenuation coefficient $\mu\left(\mathrm{cm}^{-1}\right)$ which is the fractional decreases in the photon intensity per unit path length of the absorber depends strongly on the physical density of the absorber. 


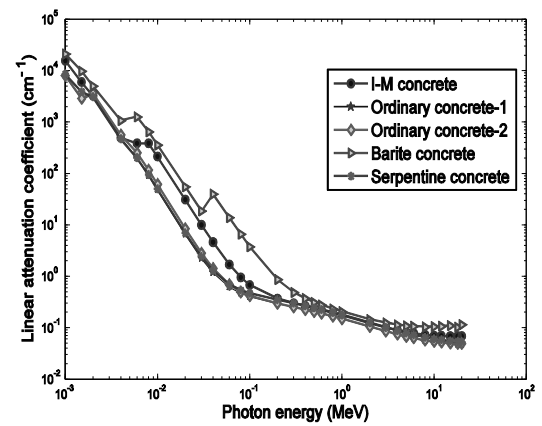

Fig. 4. Variation of total linear attenuation coefficients of different concretes with photon energy.

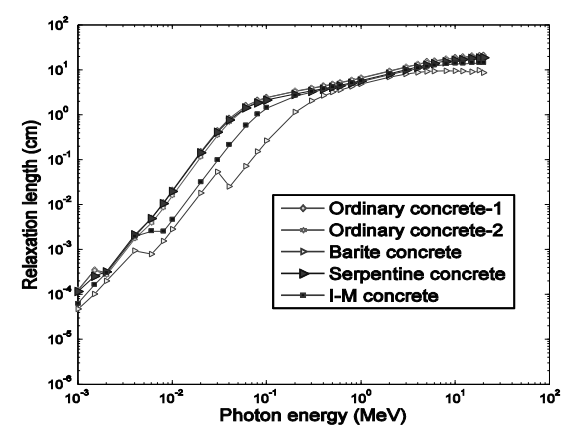

Fig. 5. Variation of relaxation lengths of photons in different concretes with energy.

Energy dependence of linear attenuation coefficients of I-M concrete are shown graphically in Fig. 4. I-M concrete has the higher values of $\mu\left(\mathrm{cm}^{-1}\right)$ than ordinary concretes and serpentine in the low energy region for its higher density and effective atomic number which reflect its effectiveness. One important thing is seen from the figure that in spite of higher density of serpentine than ordinary concretes, it has the lowest value of $\mu\left(\mathrm{cm}^{-1}\right)$ due to its lower effective atomic number. Because $\mu\left(\mathrm{cm}^{-1}\right)$ increases linearly with physical density but as fourth power of atomic number of the element in this energy range. Sharp peaks in the curve indicate the photoelectric edge.

Table 3. Comparison of mass attenuation coefficients $\left(\mathrm{cm}^{2} / \mathrm{g}\right)$ of different concretes for some widely used gamma ray source energies.

\begin{tabular}{llllllll}
\hline \multirow{2}{*}{$\begin{array}{l}\text { Concrete } \\
\text { type }\end{array}$} & \multicolumn{7}{c}{ Photon energy (MeV) } \\
\cline { 2 - 8 } & 0.364 & 0.662 & 1.173 & 1.250 & 1.332 & 2.750 & 7.120 \\
\hline I-M & 0.09927 & 0.07575 & 0.05729 & 0.05527 & 0.05366 & 0.03794 & 0.02688 \\
Ordinary-1 & 0.10285 & 0.07988 & 0.06062 & 0.05846 & 0.05680 & 0.03942 & 0.02566 \\
Ordinary-2 & 0.10011 & 0.07750 & 0.05889 & 0.05678 & 0.05519 & 0.03843 & 0.02545 \\
Barite & 0.12323 & 0.07839 & 0.05723 & 0.05404 & 0.05394 & 0.03831 & 0.03138 \\
Serpentine & 0.10692 & 0.08299 & 0.06304 & 0.06083 & 0.05905 & 0.04088 & 0.02619 \\
\hline
\end{tabular}

Sharp decrease in $\mu\left(\mathrm{cm}^{-1}\right)$ can be explained by the dependence of photoelectric absorption on photon energy. In the compton scattering region $\mu\left(\mathrm{cm}^{-1}\right)$ depends on the physical density and effective electron density of the absorber. I-M concrete is better than the ordinary concretes in this energy range for its higher density although its effective electron density is lower than both the ordinary concretes. Serpentine is slightly better than I-M concrete due to its highest effective electron density. The highest physical density of barite overcome the effect of its lowest effective electron density and becomes most effective shielding in this region. As the photon energy increases the probability of 
pair production increases which is indicated by the smooth rise in the curve. The higher physical density and effective atomic number of I-M concrete makes it a better shielding material than serpentine and ordinary concretes in this energy range.

Table 4. Comparison of linear attenuation coefficients $\left(\mathrm{cm}^{-1}\right)$ of different concretes for some widely used gamma-ray source energies.

\begin{tabular}{llllllll}
\hline \multirow{2}{*}{$\begin{array}{l}\text { Concrete } \\
\text { type }\end{array}$} & \multicolumn{7}{c}{ Photon energy (MeV) } \\
\cline { 2 - 8 } & 0.364 & 0.662 & 1.173 & 1.250 & 1.332 & 2.750 & 7.120 \\
\hline I-M & 0.27597 & 0.21059 & 0.15927 & 0.15365 & 0.14917 & 0.10547 & 0.07473 \\
Ordinary-1 & 0.23656 & 0.18372 & 0.13942 & 0.13445 & 0.13063 & 0.09066 & 0.05902 \\
Ordinary-2 & 0.23525 & 0.18214 & 0.13840 & 0.13342 & 0.12970 & 0.09031 & 0.05982 \\
Barite & 0.41283 & 0.26262 & 0.19171 & 0.18104 & 0.18071 & 0.12835 & 0.10513 \\
Serpentine & 0.27799 & 0.21578 & 0.16390 & 0.15816 & 0.15352 & 0.10629 & 0.06808 \\
\hline
\end{tabular}

Half value layer and tenth value layer of different types of concretes for some common gamma energies are compared in Table 5. For all the energies the values of HVL and TVL of I-M concrete is much lower than the ordinary concretes which reflects the shielding effectiveness of I-M concrete. It is also equally as effective as serpentine. Less amount of I-M concrete will reduce the cost and space required for shielding. Barite has the minimum values of HVL and TVL due to its highest physical density and effective atomic number. Relaxation length which is also an important shielding parameter is highly energy dependent. Fig. 5 depicts the variation of relaxation length with photon energy.

Table 5. Comparison of HVL and TVL of different concretes for some common gamma-ray source energies.

\begin{tabular}{|c|c|c|c|c|c|c|c|c|c|c|}
\hline \multirow{3}{*}{$\begin{array}{l}\text { Photon } \\
\text { energy } \\
(\mathrm{MeV})\end{array}$} & \multicolumn{10}{|c|}{ Concrete type } \\
\hline & \multicolumn{2}{|c|}{ I-M } & \multicolumn{2}{|c|}{ Ordinary-1 } & \multicolumn{2}{|c|}{ Ordinary-2 } & \multicolumn{2}{|c|}{ Barite } & \multicolumn{2}{|c|}{ Serpentine } \\
\hline & $\begin{array}{l}\text { HVL } \\
(\mathrm{cm})\end{array}$ & $\begin{array}{l}\text { TVL } \\
(\mathrm{cm})\end{array}$ & $\begin{array}{l}\text { HVL } \\
(\mathrm{cm})\end{array}$ & $\begin{array}{l}\text { TVL } \\
(\mathrm{cm})\end{array}$ & $\begin{array}{l}\text { HVL } \\
(\mathrm{cm})\end{array}$ & $\begin{array}{l}\text { TVL } \\
(\mathrm{cm})\end{array}$ & $\begin{array}{l}\text { HVL } \\
(\mathrm{cm})\end{array}$ & $\begin{array}{l}\text { TVL } \\
(\mathrm{cm})\end{array}$ & $\begin{array}{l}\text { HVL } \\
(\mathrm{cm})\end{array}$ & $\begin{array}{l}\text { TVL } \\
(\mathrm{cm})\end{array}$ \\
\hline 0.364 & 2.51 & 8.33 & 2.93 & 9.72 & 2.95 & 9.78 & 1.68 & 5.57 & 2.49 & 8.27 \\
\hline 0.662 & 3.29 & 10.92 & 3.77 & 12.52 & 3.80 & 12.63 & 2.64 & 8.76 & 3.21 & 10.66 \\
\hline 1.173 & 4.35 & 14.44 & 4.97 & 16.50 & 5.01 & 16.62 & 3.61 & 12.00 & 4.23 & 14.03 \\
\hline 1.250 & 4.51 & 14.97 & 5.15 & 17.11 & 5.19 & 17.24 & 3.83 & 12.70 & 4.38 & 14.54 \\
\hline 1.332 & 4.65 & 15.42 & 5.30 & 17.61 & 5.34 & 17.73 & 3.83 & 12.73 & 4.51 & 14.98 \\
\hline 2.750 & 6.57 & 21.81 & 7.64 & 25.37 & 7.67 & 25.47 & 5.40 & 17.92 & 6.52 & 21.64 \\
\hline 7.120 & 9.27 & 30.78 & 11.74 & 38.97 & 11.59 & 38.45 & 6.59 & 21.88 & 10.18 & 33.78 \\
\hline
\end{tabular}

The increase of relaxation length with photon energy can be explained by the higher penetrating power of energetic photons and their interaction mechanism. The lower is the relaxation length, the higher is the attenuation. Hence I-M concrete is better than ordinary concretes and serpentine for its lower relaxation length. 
The transmission factors are calculated for some common gamma sources using Eq. (1). Variation of transmission factors with penetration distance in I-M concrete at different photon energies are shown in Figs 6-12 and compared with other concretes. It is clear from all the figures that barite has the lowest transmission because of its highest physical density and effective atomic number. I-131 which is commonly used in thyroid cancer treatment emits gamma photon of energy $364 \mathrm{keV}$. It is seen from the Fig. 6 that the transmission factors for I-M concretes at $364 \mathrm{KeV}$ are lower than the ordinary concretes and nearly equal to the values for serpentine.

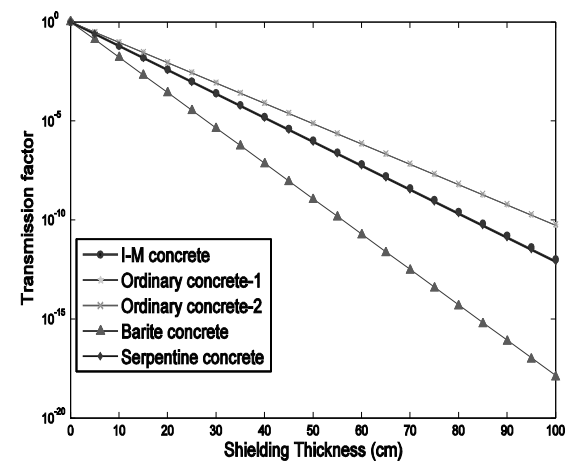

Fig. 6. Variation of transmission factor with shielding thickness at $364 \mathrm{keV}$.

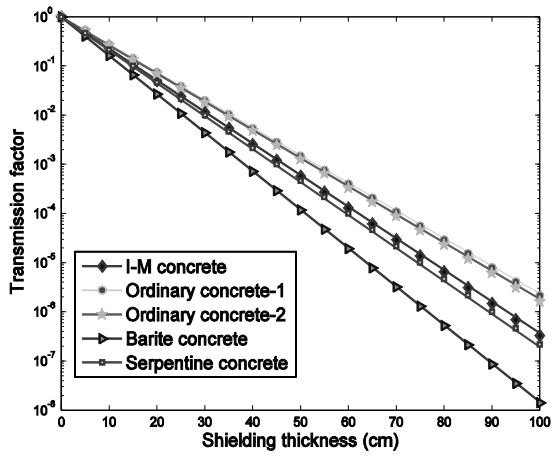

Fig. 8. Variation of transmission factor with shielding thickness at $1173 \mathrm{keV}$.

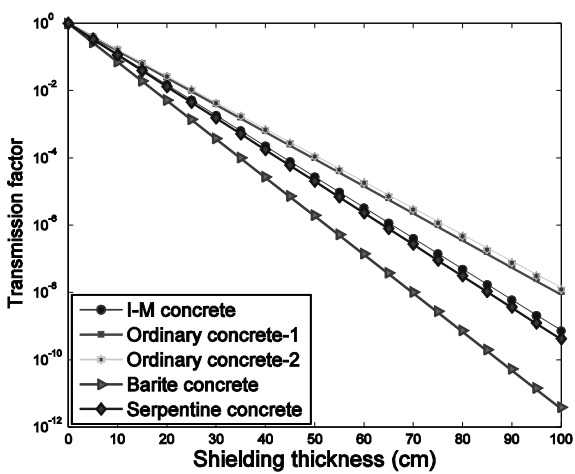

Fig. 7. Variation of transmission factor with shielding thickness at $662 \mathrm{keV}$.

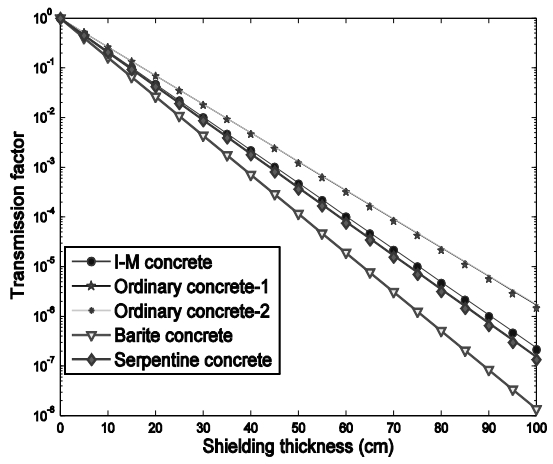

Fig. 9. Variation of transmission factor with shielding thickness at $1250 \mathrm{keV}$.

Cesium-137 is a nuclear fission product and emits a single gamma of energy 662

$\mathrm{KeV}$. At this energy I-M concrete has higher attenuation i.e. lower transmission than ordinary concretes for its higher physical density. Serpentine is slightly better than I-M at this energy due to its high effective electron density. Co-60 which is a neutron activation product is a radioisotope of cobalt and decays to nickel by beta decay and emitting two 
gamma rays of energies $1.173 \mathrm{MeV}$ and $1.332 \mathrm{MeV}$, and the average of which is 1.25 Mev. Transmission factors at these energies are shown in Figs 8-10. I-M concrete is also better than both the ordinary concretes because of its lower transmission at these energies. Due to the dominance of Compton scattering at these energies, serpentine is slightly better than I-M concrete.

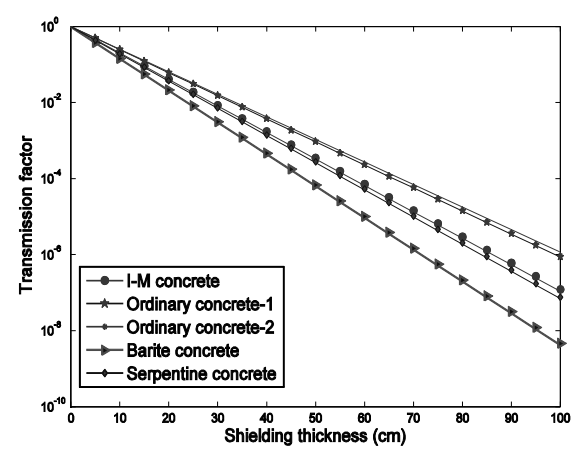

Fig. 10. Variation of transmission factor with shielding thickness at $1332 \mathrm{keV}$.

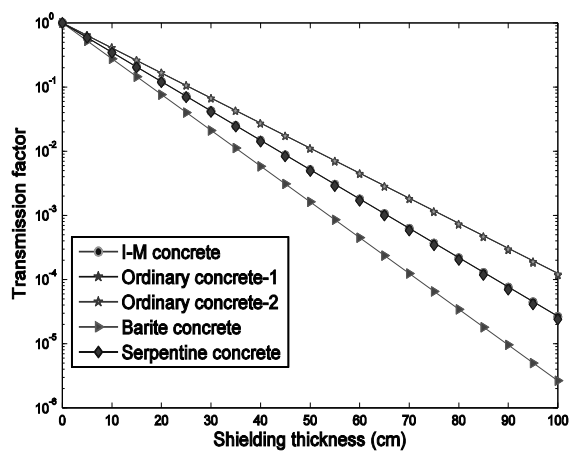

Fig. 11. Variation of transmission factor with shielding thickness at $2750 \mathrm{keV}$.

Fig. 11 describes the transmission factors at $2.75 \mathrm{MeV}$ gamma which is emitted by $\mathrm{Na}-24$, a coolant activation product of the sodium cooled fast breeder reactor. N-16 is also a coolant activation product of the light water reactor emits $7.12 \mathrm{MeV}$ gammas which are highly penetrating. Since at this energy pair production starts to dominate the interaction, I-M concrete has lower transmission factor than other concretes except barite for its high density and effective atomic number.

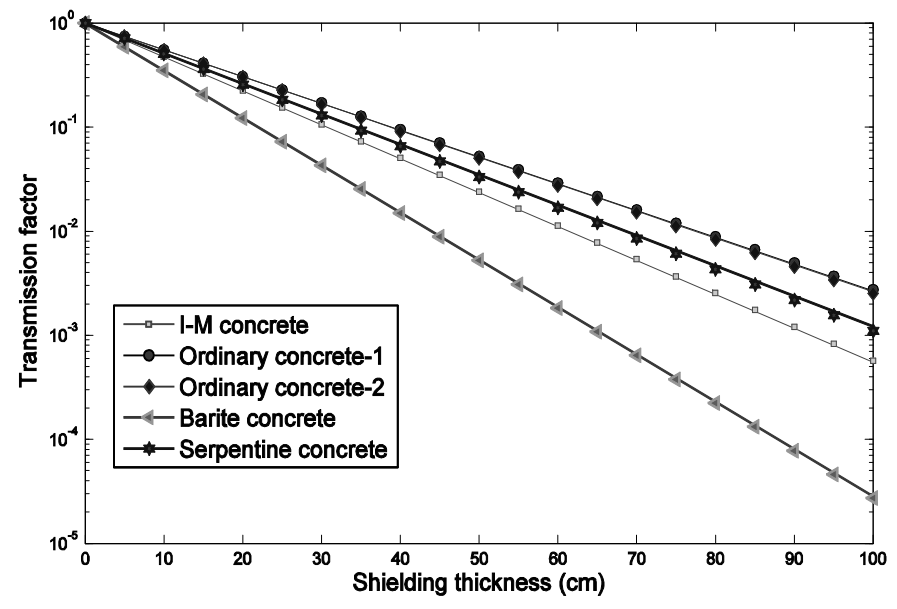

Fig. 12. Variation of transmission factor with shielding thickness at $7120 \mathrm{keV}$. 


\section{CONCLUSION}

The mass attenuation coefficient, linear attenuation coefficient, HVL, TVL and relaxation length calculated in this study reflects the good quality of I-M concrete. The transmission curves presented here can be used for practical shielding calculation. The result of this study will provide some useful information about the shielding material data base which will facilitate the practical shielding design problem. It can be concluded that the I-M concrete is superior to ordinary concretes and in some cases to serpentine. I-M concrete will be an excellent, cost effective and less space consuming shielding material against gamma radiation. It can be used as a biological shield for reactors, accelerators, $\mathrm{x}$-ray installation, and other hot laboratories as well as commercial gamma ray irradiation facilities.

\section{REFERENCES}

Akkurt, I., C. Basyigit, S. Kilincarslan, B. Mavi and A. Akkurt. 2006. Radiation shielding of concretes containing different aggregates. Cement and concrete composites 28: 153-157.

Akkurt, I., H.Akyıldırım, B. Mavi, S. Kilincarslan and C. Basyigit. 2010. Photon attenuation coefficients of concrete includes barite in different rate. Annals of Nuclear Energy 37: 910914.

Akkurt, I., R.Altindag, K. Gunoglu and H. Sarıkaya. 2012. Photon attenuation coefficients of concrete including marble aggregates. Annals of Nuclear Energy 43: 56-60.

Akkurt, I. and A.M. El-Khayatt. 2013. The effect of barite proportion on neutron and gamma-ray shielding. Annals of Nuclear Energy 51: 5-9.

Ahmed, F.U., S.I. Bhuiyan, A.S. Mollah and M.M. Rahman. 1992. Measurement of gamma ray shielding properties of ilmenite-magnetite concrete and polyborn slabs using a ${ }^{252} \mathrm{cf}$ source. Nuclear Technology 98: 379-386.

Ahmed, F.U., S.I.Bhuiyan, A.S. Mollah, M.R. Sarder, M. Q. Huda, M. Rahman and M.A.W. Mondal. 1999. Studies on the shielding properties of polyboron and ilmenite-magnetite concrete using a reactor beam. Nuclear Technology 126: 196-204.

Bhuiyan, S.I., F.U. Ahmed, A.S. Mollah and M.A. Rahman. 1991. Studies of neutron shielding properties of ilmenite- magnetite concrete using a ${ }^{252}$ cf source. Nuclear Technology 93: 357-361.

Cember, H. and E. Jonson. 2009. Introduction to Health Physics ( $4^{\text {th }}$ ed.), Department of Environmental and Radiological Health Sciences, Colorado State University.

El-Khayatt, A.M. 2010. Radiation shielding of concretes containing different lime/silica ratios. Annals of Nuclear Energy 37: 991-995.

El-Khayatt, A.M. and I. Akkurt. 2013. Photon interaction, energy absorption and neutron removal cross section of concrete including marble. Annals of Nuclear Energy 60: 8-14.

El-Khayatt, A.M. and I. Akkurt. 2013. Photon interaction, energy absorption and neutron removal cross section of concrete including marble. Annals of Nuclear Energy 60: 8-14.

Hubbell, J.H. and S.M. Seltzer. 1995. Tables of X-ray mass attenuation coefficients and mass energy-absorption coefficients $1 \mathrm{keV}$ to $20 \mathrm{MeV}$ for elements $\mathrm{Z}=1$ to 92 and 48 additional substances of dosimetric interest. NISTIR-5632. National Institute of Standards and Technology, Gaithersburg.

Mollah, A.S., G.U. Ahmad and S.R. Husain. 1992. Measurement of neutron shielding properties of heavy concrete using a ${ }^{252} \mathrm{cf}$ source. Nuclear Engineering and Design 135: 321-325. 
Oto, B. and A. Gür. 2013. Gamma-ray shielding of concretes including magnetite in different rate. International Journal of Physical Sciences 8(8): 310-314.

Rezaei-Ochbelagh, D., S. Azimkhani and H. Gasemzadeh Mosavinejad. 2012. Gamma-ray shielding properties of concrete with different percentages of lead. Nuclear Science and Techniques 23: 215-218.

Sharifi, Sh., R. Bagheri and S.P. Shirmardi. 2013. Comparison of shielding properties for ordinary, barite, serpentine and steel magnetite concretes using MCNP-4C code and available experimental results. Annals of Nuclear Energy 53: 529-534.

Stankovic, S.J., R.D. Ilic, K. Jankovic, D. Bojovic and B. Loncar. 2010. Gamma radiation absorption characteristics of concrete with components of different type materials. 117: Acta Physica Polonica A No. 5.

Yılmaz, E., H. Baltas, E. Kırıs, I.Ustabas, U. Cevik and A.M. El-Khayatt. 2011. Gamma ray and neutron shielding properties of some concrete materials. Annals of Nuclear Energy 38: 22042212.

(Received revised manuscript on 24 February, 2016) 